\title{
The motor cortex wants the full story: The influence of sentence context on corticospinal excitability in action language processing
}

\author{
Dupont $\mathrm{W}^{1}$, Lebon $\mathrm{F}^{1}$, Papaxanthis $\mathrm{C}^{1}$, Madden-Lombardi $\mathrm{C}^{12}$ \\ IINSERM UMR1093-CAPS, Université Bourgogne Franche-Comté, UFR des Sciences \\ du Sport, F-21000, Dijon. ${ }^{2}$ Centre National de la Recherche Scientifique (CNRS), France
}

According to the embodied language framework, reading action verbs leads to a mental representation involving motor cortex activation. As sentence context has been shown to greatly influence the meaning of words, the present study aimed at better understanding its role in motor representations. We manipulated the presence of manual actions and sentence context. We hypothesized that context would serve to focus the representation of the described actions in the motor cortex, reflected in context-specific modulation of corticospinal excitability.

Participants read manual action verbs and non-manual verbs, preceded by a full sentence (rich context) or not (minimal context). We assessed the level of corticospinal excitability by means of transcranial magnetic stimulation pulses delivered at rest or shortly after verb presentation. The coil was positioned over the cortical representation of right first dorsal interosseous (pointer finger).

We observed a general increase of corticospinal excitability while reading both verb types in minimal context, whereas the modulation was action-specific in rich context: corticospinal excitability increased while reading manual verbs, but did not differ from baseline for non-manual verbs. These findings suggest that the context sharpens motor representations, activating the motor cortex when relevant and eliminating any residual motor activation when no action is present.

Keywords: Action language, motor representation, embodied cognition, transcranial magnetic stimulation. 


\section{Introduction}

According to the embodied language theory, researchers hypothesized a link between language processes and perceptual-motor processes [1-9]. To support this idea, many authors probed the involvement of the motor system during language processing using various methodologies, such as functional Magnetic Resonance Imaging (fRMI), Transcranial Magnetic Stimulation (TMS) and behavioural analysis. fRMI studies revealed the activation of motor and premotor areas during action verb reading [10-12]. More precisely, these authors suggested that the information described by language would be treated in the brain areas that are concerned by the concept itself; if the concept concerns sight, this will lead to processing in the visual areas. The same applies to action language, suggesting that semantic information referring to an action is processed by the sensory motor system. Specifically, Hauk et al. (2004) reported that silent reading of action words leads to somatotopic activation of the effector-related representation within the primary motor cortex. These cortical activations would explain behavioral modulation during language processing, such as improvement in squat jump $[13,14]$, and facilitation of motor response time $[15,16]$. These facilitations are present only if the linguistic content is compatible with the subsequent movement [7,17-21]. Similarly, physical training also improved linguistic comprehension $[22,23]$, suggesting that improvement in a non-linguistic domain can improve comprehension of that subject.

Nonetheless, language is a fast-process mechanism [24-27] with a precise temporality that is difficult to optimally investigate with fRMI or behavioral analysis. The high-temporal resolution of the TMS technique helps to investigate the involvement of the motor cortex in a time frame similar to action language processing. When a TMS pulse is applied over the primary motor cortex, a motor-evoked potential (MEP) is recorded few milliseconds later in the target muscle. MEP amplitude is a marker of corticospinal excitability. Papeo et al. (2009) observed an increase of corticospinal excitability only $500 \mathrm{~ms}$ after verb presentation, suggesting that the motor cortex is implicated in post-conceptual processing. However, Tomasino et al. (2008) did not observe any MEP increase, while Buccino et al. (2005) observed MEP decrease during language processing. These discrepancies may be explained by the type of linguistic stimuli, with the presentation of isolated verbs [28], pronoun-verb pairs [29], or short sentences [30]. 
Outside the laboratory, natural human communication involves rich sentential contexts, with complex sentences. In our view, context is of importance in language processing to understand more effectively and precisely the action described in the sentence. In the current study, we investigated the importance of sentential context during the processing of action language, questioning whether corticospinal excitability is greater when a sentential context is present. Participants were instructed to read manual-action or non-manual verbs that appeared either in a rich sentential context (full sentence) or in a minimal context (pronounverb pair). TMS pulses were delivered over the pointer finger area of the left primary motor cortex at three latencies after the verb presentation $(200,300$, or $400 \mathrm{~ms})$ to better capture individual corticospinal modulation during reading. We hypothesize that context serves to sharpen motor representations, reflected in context-specific modulation of corticospinal excitability. We expect to find an effect of Action whereby manual action verbs yield greater corticospinal excitability than non manual verbs, and we anticipate this effect to be larger when verbs are presented in sentence context rather than minimal context.

\section{Material and method}

\section{Participants}

Eighteen right-handed adults ( 5 women; mean age $=24$ years-old; range 20-29 years) participated in the experiment. Handedness was assessed by the Edinburgh inventory [31]. All participants had normal or corrected-to-normal vision, without neurological, physical and cognitive pathologies. Volunteers followed a medical visit before their inclusion into the TMS protocol and confirmed their participation with written consent. The local Ethics Committee approved experimental protocol and procedures in accordance with the Declaration of Helsinki.

\section{Stimuli}

One hundred and forty-four French verbs were generated; half referred to Manual Actions (e.g., "I scrub") and half were Non-Manual (e.g., "I ignore", I kick"). These verbs were presented either in a Rich context that helped to specify the verb (e.g., "I see a stain on my shirt and I scrub it" or "I see a stain on my shirt and I ignore it"), or in Minimal context (e.g., "I scrub" or "I ignore; see Table 1 for details). Sentences always appeared in the firstperson present tense. All rich-context sentences were created such that the target verb occurred at the end of the sentence (see Figure 1). This final pronoun-verb segment was 
presented alone on a subsequent screen after the beginning of the sentence was presented, thus yielding an identical or very similar presentation screen to the minimal sentence version.

A list was generated, in which 36 of the manual action verbs, and 36 of the non-manual verbs occurred within rich sentence contexts, while the other 36 manual action verbs, and 36 non-manual verbs occurred in minimal sentence context. A second list presented these same verbs in the opposite rich and minimal context versions. Each manual action verb (to scrub) was paired with a non-manual verb (to ignore), sharing the same rich-context sentence (I see a stain on my shirt and I scrub/ignore it), and each verbal stimulus only appeared once in the list. Thereby, across participants each verb appeared in both conditions. For example, for the scrub/ignore pair, if a given participant read the minimal sentence "I scrub", she/he would also read the rich context sentence "I see a stain on my shirt and I ignore it". And another participant would read "I ignore" as well as " I see a stain on my shirt and I scrub it". In addition, TMS latencies were counterbalanced within each list.

Table 1. Example of lexical stimuli used in experiment.

\begin{tabular}{|c|c|c|c|}
\hline \multicolumn{2}{|c|}{ Manual Action } & \multicolumn{2}{|c|}{ Non-Manual } \\
\hline Minimal Context & Rich Context & Minimal context & Rich context \\
\hline Je mélange & $\begin{array}{l}\text { Les cartes sont sur la } \\
\text { table et je les mélange }\end{array}$ & Je memorise & $\begin{array}{l}\text { Les cartes sont sur la table } \\
\text { et je les mémorise }\end{array}$ \\
\hline I mix & $\begin{array}{l}\text { The cards are on the } \\
\text { table and I mix them }\end{array}$ & I memorize & $\begin{array}{l}\text { The cards are on the table } \\
\text { and I memorize them }\end{array}$ \\
\hline Je frotte & $\begin{array}{l}\text { Je vois une tache sur } \\
\text { mon t-shirt et je la frotte }\end{array}$ & J'ignore & $\begin{array}{l}\text { Je vois une tache sur mon } \\
\text { t-shirt et je l'ignore }\end{array}$ \\
\hline I scrub & $\begin{array}{l}\text { I see a stain on my shirt } \\
\text { and I scrub it }\end{array}$ & I ignore & $\begin{array}{l}\text { I see a stain on my shirt } \\
\text { and I ignore it }\end{array}$ \\
\hline Je ferme & $\begin{array}{l}\text { L'enveloppe est prête et } \\
\text { je la ferme }\end{array}$ & Je relis & $\begin{array}{l}\text { L'enveloppe est prête et je } \\
\text { la relis }\end{array}$ \\
\hline I close & $\begin{array}{l}\text { The envelope is ready } \\
\text { and I am closing it }\end{array}$ & I reread & $\begin{array}{l}\text { The envelope is ready and } \\
\text { I reread it }\end{array}$ \\
\hline J'accorde & $\begin{array}{l}\text { La nouvelle guitare est } \\
\text { très belle et je l'accorde }\end{array}$ & J'écoute & $\begin{array}{l}\text { La nouvelle guitare est très } \\
\text { belle et je l'écoute }\end{array}$ \\
\hline I tune & $\begin{array}{l}\text { The new guitar is very } \\
\text { beautiful and I tune }\end{array}$ & I listen & $\begin{array}{l}\text { The new guitar is very } \\
\text { beautiful and I listen }\end{array}$ \\
\hline Je paraphe & $\begin{array}{l}\text { Après avoir lu le contrat, } \\
\text { je le paraphe }\end{array}$ & Je contemple & $\begin{array}{l}\text { Après avoir lu le contrat, } \\
\text { je le contemple }\end{array}$ \\
\hline I initial & $\begin{array}{l}\text { After reading the } \\
\text { contract, I initial it }\end{array}$ & I contemplate & $\begin{array}{l}\text { After reading the contract, } \\
\text { I contemplate it }\end{array}$ \\
\hline
\end{tabular}




\section{Procedure}

Participants sat in an armchair. Stimuli were presented on a 19-inch LCD monitor by Neurostim software, which controlled TMS triggering and synchronized physiological recordings. Throughout the recording, participants were instructed not to move, while they silently read sentences. Corticospinal excitability was recorded at rest, as well as during a reading task at various stimulation latencies (200, 300 or $400 \mathrm{~ms}$ after the verb onset). These latencies were chosen based on electroencephalogram studies showing 200ms as a minimal latency for semantic process in anterior regions [24,25]. In addition, later latencies are related to changes of P300 in parietal and frontal regions [25], but also N400 in posterior regions $[26,32]$ when participants read action words compared to abstract words.

Before the experimental session, a familiarization session was conducted, in which participants saw four trials, each with a fixation cross, followed by a minimal sentence or a rich sentential context, then a break before the next trial. Once the participant understood this procedure, four new practice trials were presented, now including TMS pulses after the appearance of the target verb. The experimental session was divided into 3 blocks, each comprised of 56 trials, yielding 168 trials total in the experiment. Among the 56 trials in each block, 8 trials were interspersed with TMS pulses only at rest (fixation cross), which served as reference stimulations and allowed comparisons across experimental conditions in that block. Moreover, to avoid mental fatigue and lack of concentration, there was a two-minute break between each block, allowing each participant to be as attentive as possible during experimental blocks. In each block, the number of stimulations was equally distributed between all conditions, but also between the three different stimulation latencies. 


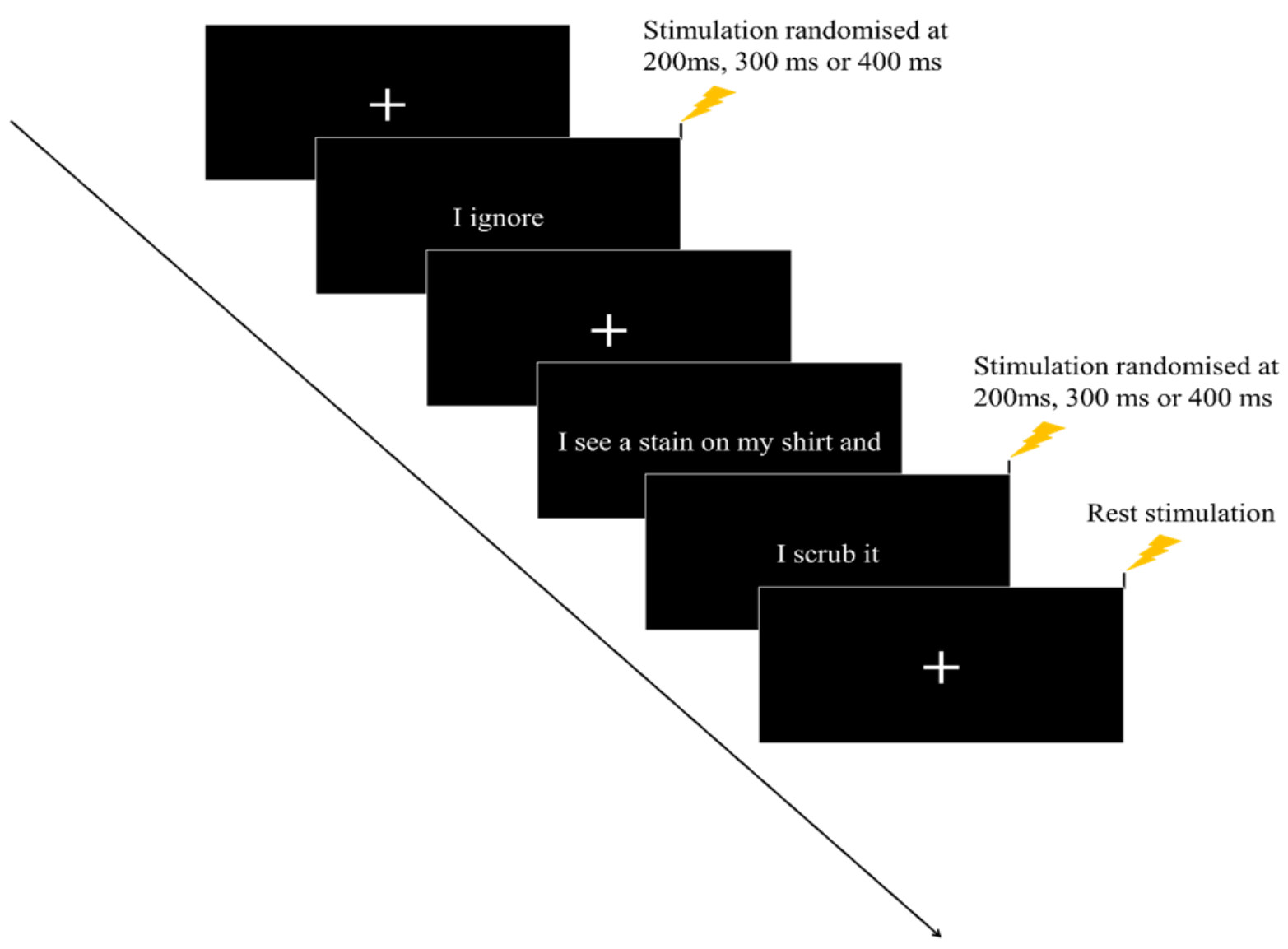

Figure 1.Experimental procedure. Sentences in a Minimal or Rich context were presented on a screen in front of the participant. Single-pulse TMS was triggered over the left hemisphere and motor-evoked potentials recorded in the right index finger.

\section{TMS}

Single-pulse TMS was generated from an electromagnetic stimulator Magstim 200 (Magstim Company Ltd, Whitland) and using a figure-of-eight coil (70 $\mathrm{mm}$ in diameter). The coil was placed over the contralateral left hemisphere to target the motor area of the First Dorsal Interosseous (FDI) muscle of the right hand. The coil rested tangential to the scalp with the handle pointing backwards and laterally at a $45^{\circ}$ angle away from the midline. First, the mapping of the motor cortex of each participant determined the precise stimulation site (hotspot) corresponding to the location, where the MEPs amplitude of the FDI muscle was the highest and the most consistent for the same stimulation intensity. The resting motor threshold of each participant was determined as the minimal intensity of TMS necessary to induce a MEP of $50 \mu \mathrm{V}$ peak-to-peak amplitude in the right FDI muscle for 4 trials out of 8 . During the experimental session, TMS intensity was set at $130 \%$ of the resting motor threshold. 


\section{EMG recording}

The EMG signal was recorded through 10mm-diameter surface electrodes (Contrôle Graphique Médical, Brice Comte-Robert, France) placed over the FDI and Abductor Digiti Minimi (ADM) muscles of the right hand, serving as target and control effectors respectively. Before placing the electrodes, the skin was shaved and cleaned in order to reduce the noise in the EMG signal $(<10 \mu \mathrm{V})$. The EMG signals were amplified and bandpass filtered on-line (10-5000 Hz, Biopac Systems Inc.) and digitized at $2000 \mathrm{~Hz}$ for off-line analysis. We also recorded the EMGrms signal from each muscle.

\section{Data and statistical analysis}

EMG data were extracted with Matlab (The MathWorks, Natick, Massachusetts, USA) and we measured peak-to-peak MEP amplitude. Data falling 2 SDs above or below individual means for each experimental condition were removed before analysis (4.02\% of total). Then, the average MEP amplitude for each condition was normalized with reference to baseline MEP amplitude (rest). Importantly, no analysis on the timing factor was performed as we rather isolated the peak of excitability among the three stimulation times for each participant in each condition. This accounts for individual variability in the semantic processing of the action over time, and allows us to tap into the action representation at its temporal peak. Finally, Box Plot statistics identified extreme mean values for three participants, who were excluded from the final analysis. Statistics and data analyses were performed using the software Statistica (Stat Soft, France).

Data normality was confirmed by the Shapiro-Wilk test. To assess the influence of Action and Context on corticospinal excitability, we performed a 2 by 2 repeated measures ANOVA with Action (Manual Action vs. Non-Manual) and Context (Minimal vs. Rich) as within-subject factors. Based on our a priori hypothesis, we conducted contrast analyses, in which separate one-tailed t-tests compared Manual Action and Non-Manual verbs in each Context condition. Then, one-sample t-tests were used to compare normalized MEPs at zero for each condition to assess whether corticospinal excitability during reading changed from baseline. Finally, in order to ensure that our results were not contaminated by muscular preactivity, we tested whether the EMGrms before the TMS artifact of our experimental conditions was different from zero with Wilcoxon tests.

All analyses were performed on the FDI and ADM muscles. The data are presented as mean values ( \pm standard error) and the alpha value was set at 0.05 . 


\section{Results}

The initial ANOVA on FDI data, the main effector in manual action verbs, revealed a main effect of Action $\left(\mathrm{F}_{1,14}=8.146, \mathrm{p}=0.012, \eta \mathrm{p}^{2}=0.367\right)$, with larger MEP ratios for Manual Action verbs $(14.07 \pm 16.72 \%)$ than Non-Manual verbs $(6.00 \pm 10.38 \%)$. We did not observe any main effect of Context $\left(\mathrm{F}_{1,14}=0.002, \mathrm{p}=0.950, \eta \mathrm{p}^{2}=0.0002\right)$ nor Action by Context interaction $\left(\mathrm{F}_{1,14}=0.890 \mathrm{p}=0.361, \eta \mathrm{p}^{2}=0.059\right)$.

As the main effect of action was hypothesized to be stronger within the rich context, we conducted two t-tests (one-tailed) where the action effect was tested separately under rich and minimal context conditions. This analysis revealed a main effect of Action for the rich context condition ( $\mathrm{p}=0.030, \mathrm{~d}=0.82$; Mean ratios: $15.91 \pm 18.33 \%$ and $4.33 \pm 9.82 \%$ for Manual Action verbs and Non-Manual verbs, respectively). However, the effect of Action in the minimal context was not significant $(\mathrm{p}=0.097, \mathrm{~d}=0.35$; Mean ratios: $12.24 \pm 15.35 \%$ and $7.67 \pm 10.99 \%$ for Manual Action verbs and Non-Manual verbs, respectively). Therefore, the difference between Manual Action and Non-Manual verbs appears to be driven by the rich context sentences (Figure 2). 
Manual Action

$\square$ Non-Manual

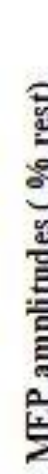

总
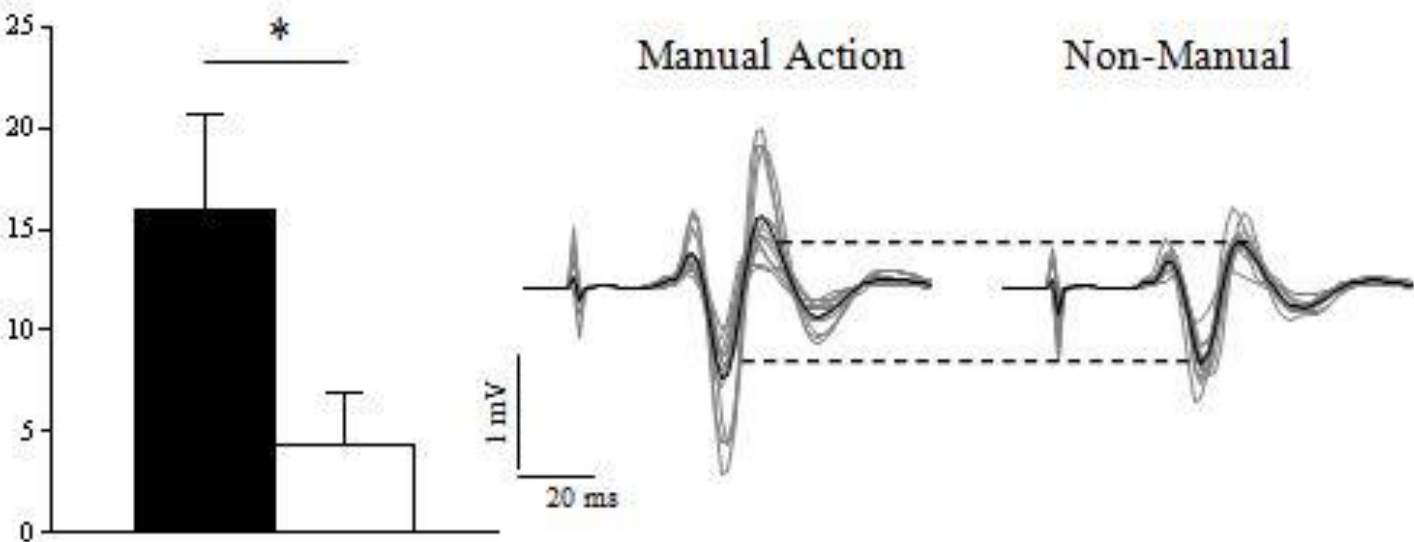

Minimal context Conditions
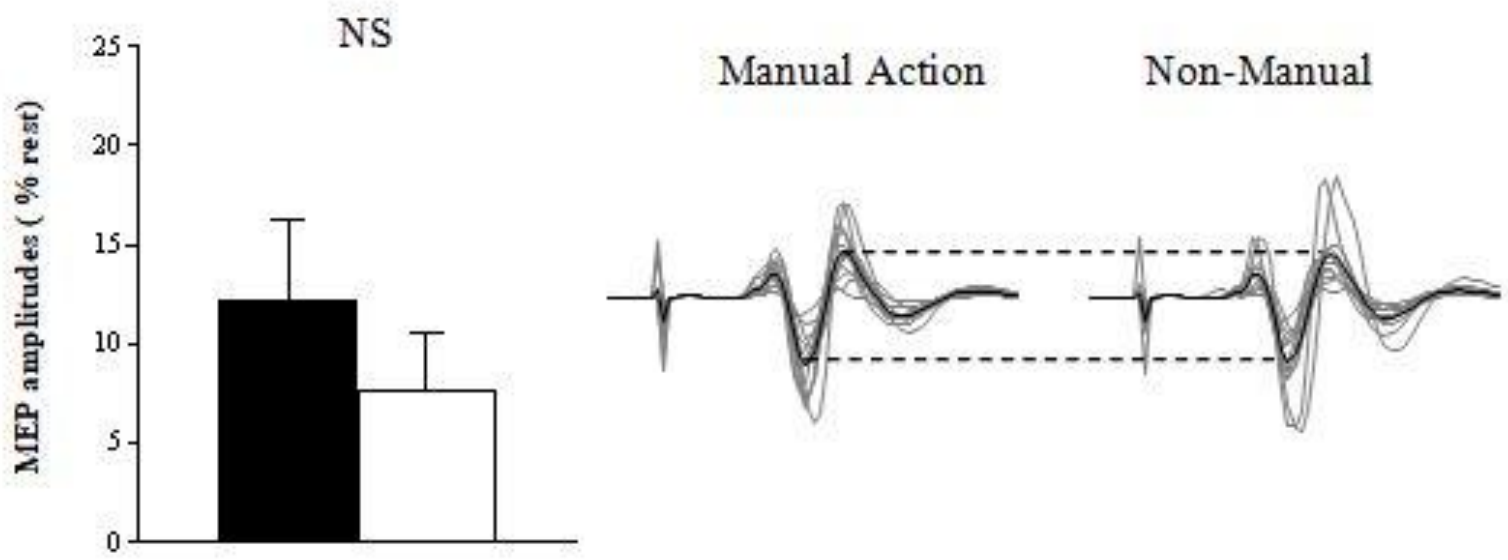

Figure 2 : Corticospinal excitability in Rich and Minimal Context. Bar plots on the left side represent normalized MEPs (Vertical bars denote the Standard Error of the mean). Contrast analyses revealed an action effect for rich context but no effect for minimal context. The right side of the panel illustrates raw MEPs of a typical subject (grey lines). The black line is the average MEP of the condition for this participant. * $=p<0.05$

Using one-sample t-tests, we found that normalized MEPs of all conditions were different from baseline (all p's $<0.05$ ), except for Non-Manual verbs in the rich context $(\mathrm{p}=0.10)$. 
Recordings of the ADM muscle were used as a control since the described actions did not involve this muscle. First focusing on corticospinal excitability, we did not observe any significant main effect of Action $\left(\mathrm{F}_{1,14}=0.436, \mathrm{p}=0.506, \eta p^{2}=0.032\right)$ or Context $\left(\mathrm{F}_{1,14}=0.111\right.$, $\left.\mathrm{p}=0.743, \eta \mathrm{p}^{2}=0.007\right)$, nor interaction $\left(\mathrm{F}_{1,14}=0.198, \mathrm{p}=0.662, \eta \mathrm{p}^{2}=0.013\right)$. Also, normalized MEPs were not different from baseline in any condition ( $p$ 's $>0.05$ ). These findings support the somatotopic activation hypothesis that only relevant effectors will be active during the reading of action verbs.

Finally, we analyzed the EMGrms prior to TMS artifacts to test for confounds in MEP modulation. We did not observe any difference from baseline, indicating that MEP modulations were not influenced by background EMG (see Table 2 for details).

Table 2: EMGrms activity (mean $\pm S D$ ) in microVolt recorded for the first dorsal interosseous (FDI) and the abductor digiti minimi (ADM) before the TMS artifact for each condition. The p-values inside the table are the results of Wilcoxon tests for EMGrms.

\begin{tabular}{|c|c|c|c|c|c|c|c|c|c|}
\hline & & \multicolumn{4}{|c|}{ Minimal context } & \multicolumn{4}{|c|}{ Rich context } \\
\hline & \multirow{2}{*}{$\begin{array}{c}\text { Rest } \\
\text { Mean }\end{array}$} & \multicolumn{2}{|c|}{ Manual Action } & \multicolumn{2}{|c|}{ Non-Manual } & \multicolumn{2}{|c|}{ Manual Action } & \multicolumn{2}{|c|}{ Non-Manual } \\
\hline & & Mean & P-value & Mean & P-value & Mean & P-value & Mean & P-value \\
\hline FDI & $1.5 \pm 0.6$ & $1.5 \pm 0.5$ & 0.233 & $1.5 \pm 0.4$ & 0.058 & $1.3 \pm 0.2$ & 0.080 & $1.4 \pm 0.4$ & 0.172 \\
\hline ADM & $9.1 \pm 1.6$ & $9.1 \pm 1.6$ & 0.194 & $9.1 \pm 1.7$ & 0.238 & $9.1 \pm 1.6$ & 0.152 & $9.1 \pm 1.6$ & 0.205 \\
\hline
\end{tabular}

\section{Discussion}

This study challenged the idea that action-language processing automatically activates the motor cortex, but rather shows how context helps to direct this activation. We observed a context-specific modulation of corticospinal excitability, with a significant difference in MEP amplitude between manual and non-manual verbs only in the rich context, and an absence of MEP increase for non-manual verbs in the rich context (in contrast to the minimal context). This novel finding highlights the importance of sentential context in the involvement of the motor cortex during the action language processing.

The action effect observed in the present study is consistent with several studies that have shown the involvement of the motor cortex during the reading of action verbs using fMRI [10,33], EEG [25,32,34], behavioral measures [13-16,25] and TMS [29,35-38]. 
However, another set of studies did not report an activation of motor cortex during lexical decision task [39,40], or motion word comprehension [41]. The present result helps to explain the discrepancy in the literature, proposing that context is an important factor that can mitigate the involvement of the motor cortex during language processing.

The activation of the motor cortex is presumed to arise from reading events describing actions, typically verbs. However, even a non-action verb may be able to lead to some degree of motor activation if it is underspecified, because the event representation is vague. On the other hand, if the verb is well contextualized, motor representation is precise resulting in the activation of the only appropriate effectors in the motor system that are relevant to the event. This is well reflected in our results where all conditions resulted in a higher state of corticospinal excitability from the baseline, except for non-manual verbs in the rich context. This suggests that the motor cortex can be automatically activated at some level even by nonaction verbs in the absence of context (see also motor activation in abstract verbs [42] and metaphoric sentences $[43,44])$. While a rich context specifies the nature of the described situation so as to boost motor activation in the relevant effectors, it also eliminates any residual motor activation from non-manual verbs. These findings support the notion of topdown processing, emphasizing the idea that motor representation and consequently motor cortex activation are not automatically triggered but that they are dependent on the context and the task [45].

It should be mentioned that in contrast to our results, several studies have shown the action effect using linguistic stimuli similar to our minimal context condition [29,35]. This is not inconsistent with our results, in that many manual action verbs would activate the motor cortex to a greater extent than non-manual verbs out of context. However, we would expect a greater difference for these same stimuli if accompanied by more contextual information to better specify the action. Indeed, the manual nature of the meaning of some verbs is quite precise regardless of context (e.g., "I write") whereas others can be rather vague (e.g., "I take"). As mentioned above, this vagueness can even introduce motor cortex activation in verbs that are intended to be non-action stimuli. The present study demonstrates the role of context in specifying the described situation and therefore regulating primary motor cortex involvement. Nevertheless, the question remains as to whether this activation of the primary motor cortex is necessary to process action language? Researchers observed that if a disturbance of the primary motor cortex or motor areas is caused by repeated TMS during language processing, there is a decrease in performance, implying the engagement of motor 
cortex in this process [46-49]. While understanding might be disturbed, diminished, or less effective, it is not completely blocked. Although language comprehension may be able to proceed without the involvement of the primary motor cortex, our findings suggest that it may play an important role in the optimization of this process, refining linguistic understanding and making it more effective when necessary.

One potential limitation of the current study is the number of experimental trials per subject. Since we cannot know exactly when the motor representation starts and when it will be at its maximum, we have to stimulate the subject at several different latencies on separate trials, and afterwards select the peak. This can be considered a strength of our study in that we take into account individual differences in processing time, but it can also be a limitation in that we reduce the number of experimental trials. In future investigations, we plan to overcome this limitation by calibrating each subject's individual processing time prior the test session. Alternatively, we could use continuous measurement, such as EEG.

In conclusion, this study provides possible explanations for the discrepancies observed in the literature on the involvement of the (primary) motor cortex in action language processing. We found that context could be a determining factor in the activation of the motor cortex. Linguistic context serves to focus the motor representation of the described action and leads to a more precise activation of the primary motor cortex. Consistent with the idea of embodied language, the motor cortex will only be engaged in linguistic processes when the described situation implies a specific effector's involvement. It is often the context and not the verb alone that determines this involvement, thus generating motor representations.

\section{Acknowledgement}

The authors are very grateful to Cyril Sirandré for Neurostim software and the experimental setup. 


\section{References:}

1. Barsalou, L.W. (1999). Perceptual symbol systems. Behav. Brain Sci. 22, 577-609.

2. Barsalou, L.W. (2008). Grounded Cognition WHAT IS GROUNDED COGNITION ? Common Misperceptions of Grounded Cognition. Rev. Lit. Arts Am. 59, 617-45.

3. Barsalou, L.W., Simmons, W.K., Barbey, A.K., and Wilson, C.D. (2003). Grounding conceptual knowledge in modality-specific systems. Trends Cogn. Sci. 7, 84-91.

4. Jeannerod, M. (2006). Motor cognition: What actions tell the self. Oxford : University Press.

5. Decety, J., and Grèzes, J. (2006). The power of simulation: Imagining one's own and other's behavior. Brain Res. 1079, 4-14.

6. Gallese, V., and Lakoff, G. (2005). The brain's concepts: The role of the sensory-motor system in conceptual knowledge. Cogn. Neuropsychol. 22, 455-479.

7. Glenberg, A.M., and Gallese, V. (2012). Action-based language: A theory of language acquisition, comprehension, and production. Cortex 48, 905-922.

8. Zwaan, R.A., and Taylor, L.J. (2006). Seeing, acting, understanding: Motor resonance in language comprehension. J. Exp. Psychol. Gen. 135, 1-11.

9. Fischer, M.H., and Zwaan, R.A. (2008). Embodied language: A review of the role of the motor system in language comprehension. Q. J. Exp. Psychol. 61, 825-850.

10. Hauk, O., Johnsrude, I., and Pulvermüller, F. (2004). Somatotopic Representation of Action Words in Human Motor and Premotor Cortex. Neuron 41, 301-307.

11. Aziz-Zadeh, L., Wilson, S.M., Rizzolatti, G., and Iacoboni, M. (2006). Congruent embodied representations for visually presented actions and linguistic phrases describing actions. Curr. Biol. 16, 1818-23.

12. Pulvermüller, F., Hauk, O., Nikulin, V. V., and Ilmoniemi, R.J. (2005). Functional links between motor and language systems. Eur. J. Neurosci. 21, 793-797.

13. Rabahi, T., Sarraj, A.R., Fargier, P., Clouzeau, C., and Massarelli, R. (2012). Action verb and motor performance. Kinesitherapie 12, 42-46.

14. Rabahi, T., Fargier, P., Rifai Sarraj, A., Clouzeau, C., and Massarelli, R. (2013). Effect 
of Action Verbs on the Performance of a Complex Movement. PLoS One 8, e68687.

15. Andres, M., Finocchiaro, C., Buiatti, M., and Piazza, M. (2015). Contribution of motor representations to action verb processing. Cognition 134, 174-184.

16. Klepp, A., van Dijk, H., Niccolai, V., Schnitzler, A., and Biermann-Ruben, K. (2019). Action verb processing specifically modulates motor behaviour and sensorimotor neuronal oscillations. Sci. Rep. 9, 15985.

17. Dalla Volta, R., Gianelli, C., Campione, G.C., and Gentilucci, M. (2009). Action word understanding and overt motor behavior. Exp. Brain Res. 196, 403-412.

18. Gentilucci, M., Benuzzi, F., Bertolani, L., Daprati, E., and Gangitano, M. (2000). Language and motor control. Exp. Brain Res. 133, 468-490.

19. Taylor, L.J., and Zwaan, R.A. (2008). Motor resonance and linguistic focus. Q. J. Exp. Psychol. 61, 896-904.

20. Zwaan, R.A., van der Stoep, N., Guadalupe, T., and Bouwmeester, S. (2012). Language comprehension in the balance: the robustness of the action-compatibility effect (ACE). PLoS One 7, e31204.

21. van Dam, W.O., and Desai, R.H. (2017). Embodied Simulations Are Modulated by Sentential Perspective. Cogn. Sci. 41, 1613-1628.

22. Beilock, S.L., Lyons, I.M., Mattarella-Micke, A., Nusbaum, H.C., and Small, S.L. (2008). Sports experience changes the neural processing of action language. Proc. Natl. Acad. Sci. U. S. A. 105, 13269-13273.

23. Locatelli, M., Gatti, R., and Tettamanti, M. (2012). Training of manual actions improves language understanding of semantically related action sentences. Front. Psychol. 3, 547.

24. Hauk, O., Davis, M.H., Ford, M., Pulvermüller, F., and Marslen-Wilson, W.D. (2006). The time course of visual word recognition as revealed by linear regression analysis of ERP data. Neuroimage 30, 1383-400.

25. Pulvermüller, F., Härle, M., and Hummel, F. (2001). Walking or talking?: Behavioral and neurophysiological correlates of action verb processing. Brain Lang. 78, 143-168.

26. Beres, A.M. (2017). Time is of the Essence: A Review of Electroencephalography 
(EEG) and Event-Related Brain Potentials (ERPs) in Language Research. Appl. Psychophysiol. Biofeedback 42, 247-255.

27. Boulenger, V., Roy, A.C., Paulignan, Y., Deprez, V., Jeannerod, M., and Nazir, T.A. (2006). Cross-talk between language processes and overt motor behavior in the first 200 msec of processing. J. Cogn. Neurosci. 18, 1607-15.

28. Tomasino, B., Fink, G.R., Sparing, R., Dafotakis, M., and Weiss, P.H. (2008). Action verbs and the primary motor cortex: a comparative TMS study of silent reading, frequency judgments, and motor imagery. Neuropsychologia 46, 1915-26.

29. Papeo, L., Vallesi, A., Isaja, A., and Rumiati, R.I. (2009). Effects of TMS on different stages of motor and non-motor verb processing in the primary motor cortex. PLoS One 4, e4508.

30. Buccino, G., Riggio, L., Melli, G., Binkofski, F., Gallese, V., and Rizzolatti, G. (2005). Listening to action-related sentences modulates the activity of the motor system: a combined TMS and behavioral study. Brain Res. Cogn. Brain Res. 24, 355-63.

31. Oldfield, R.C. (1971). The assessment and analysis of handedness: The Edinburgh inventory. Neuropsychologia 9, 97-113.

32. Kellenbach, M.L., Wijers, A.A., Hovius, M., Mulder, J., and Mulder, G. (2002). Neural differentiation of lexico-syntactic categories or semantic features? Event-related potential evidence for both. J. Cogn. Neurosci. 14, 561-577.

33. van Dam, W.O., Rueschemeyer, S.-A., and Bekkering, H. (2010). How specifically are action verbs represented in the neural motor system: an fMRI study. Neuroimage 53, $1318-25$.

34. Xu, X., Kang, C., and Guo, T. (2016). Imageability and semantic association in the representation and processing of event verbs. Cogn. Process. 17, 175-84.

35. Innocenti, A., De Stefani, E., Sestito, M., and Gentilucci, M. (2014). Understanding of action-related and abstract verbs in comparison: a behavioral and TMS study. Cogn. Process. 15, 85-92.

36. Labruna, L., Fernández-Del-Olmo, M., Landau, A., Duqué, J., and Ivry, R.B. (2011). Modulation of the motor system during visual and auditory language processing. Exp. Brain Res. 211, 243-250. 
37. Papeo, L., Lingnau, A., Agosta, S., Pascual-Leone, A., Battelli, L., and Caramazza, A. (2015). The origin of word-related motor activity. Cereb. Cortex 25, 1668-75.

38. Scorolli, C., Jacquet, P.O., Binkofski, F., Nicoletti, R., Tessari, A., and Borghi, A.M. (2012). Abstract and concrete phrases processing differentially modulates corticospinal excitability. Brain Res. 1488, 60-71.

39. Longe, O., Randall, B., Stamatakis, E.A., and Tyler, L.K. (2007). Grammatical categories in the brain: The role of morphological structure. Cereb. Cortex 17, 18121820.

40. Perani, D., Cappa, S.F., Schnur, T., Tettamanti, M., Collina, S., Rosa, M.M., and Fazio, F. (1999). The neural correlates of verb and noun processing a PET study. Brain 122, $2337-2344$.

41. Grossman, M., Koenig, P., DeVita, C., Glosser, G., Alsop, D., Detre, J., and Gee, J. (2002). Neural representation of verb meaning: An fMRI study. Hum. Brain Mapp. 15, $124-134$.

42. Sakreida, K., Scorolli, C., Menz, M.M., Heim, S., Borghi, A.M., and Binkofski, F. (2013). Are abstract action words embodied? An fMRI investigation at the interface between language and motor cognition. Front. Hum. Neurosci. 7, 125.

43. Reilly, M., Howerton, O., and Desai, R.H. (2019). Time-course of motor involvement in literal and metaphoric action sentence processing: A TMS study. Front. Psychol. 10.

44. Desai, R.H., Conant, L.L., Binder, J.R., Park, H., and Seidenberg, M.S. (2013). A piece of the action: Modulation of sensory-motor regions by action idioms and metaphors. Neuroimage 83, 862-869.

45. Tomasino, B., and Rumiati, R.I. (2013). At the Mercy of Strategies: The Role of Motor Representations in Language Understanding. Front. Psychol. 4.

46. Repetto, C., Colombo, B., Cipresso, P., and Riva, G. (2013). The effects of rTMS over the primary motor cortex: the link between action and language. Neuropsychologia 51, $8-13$.

47. Vukovic, N., Feurra, M., Shpektor, A., Myachykov, A., and Shtyrov, Y. (2017). Primary motor cortex functionally contributes to language comprehension: An online rTMS study. Neuropsychologia 96, 222-229. 
48. Courson, M., Macoir, J., and Tremblay, P. (2018). A facilitating role for the primary motor cortex in action sentence processing. Behav. Brain Res. 336, 244-249.

49. Willems, R.M., Labruna, L., D’Esposito, M., Ivry, R., and Casasanto, D. (2011). A functional role for the motor system in language understanding: evidence from thetaburst transcranial magnetic stimulation. Psychol. Sci. 22, 849-54. 